\title{
Iron-carbon hybrid capacitor: A proof-of-concept study
}

\author{
V R CHARI, S R ARAVAMUTHAN and A K SHUKLA* \\ Solid State and Structural Chemistry Unit, Indian Institute of Science, Bangalore 560 012, India
}

MS received 16 December 2013; revised 29 January 2014

\begin{abstract}
In the present study, cost-intensive Ni electrode is replaced by high surface-area activated carbon (AC) cathode and the possibility of the Fe anode, used in Ni-Fe battery, to function as Fe-C hybrid capacitor has been examined. The electrochemical properties of $\mathrm{Fe}-\mathrm{C}$ hybrid capacitor assembly are studied using cyclic voltammetry (CV) and galvanostatic charge-discharge cycles. Over 100 galvanostatic charge-discharge cycles for $\mathrm{Fe}-\mathrm{C}$ hybrid capacitor are carried out and a maximum capacitance of $24 \mathrm{~F} \mathrm{~g}^{-1}$ is observed.
\end{abstract}

Keywords. Hybrid capacitor; $\alpha$-Fe; $\mathrm{Fe}_{3} \mathrm{O}_{4}$; alkaline electrolyte.

\section{Introduction}

Batteries store energy faradaically in chemical reactants capable of generating charge while electrochemical capacitors store energy directly as charge. This limits the performance and cycle-life of batteries. By contrast, electrochemical capacitors rely on carbon-based structures utilizing electrical-double-layer-capacitance effect based on non-faradaic accumulation of electrostatic charge at the electrolyte/carbon interface through reversible ion-adsorption onto the carbon surface of the electrodes. Accordingly, electrochemical capacitors have significantly high cycle-life. A combination of faradaic and non-faradaic components would generate electrochemical capacitors that exhibit high capacitance for pulse power as well as sustained energy. These electrochemical capacitors are referred to as hybrid ultracapacitors or hybrid supercapacitors.

Recently, a rapidly rechargeable nickel-iron (Ni-Fe) battery has been reported that can deliver an energy density of $120 \mathrm{Wh} \mathrm{kg}^{-1}$ and a power density as high as $15 \mathrm{~kW} \mathrm{~kg}^{-1}$ (Wang et al 2012). These features undoubtedly provide a new generation of $\mathrm{Ni}-\mathrm{Fe}$ batteries. However, the nickel electrode in the $\mathrm{Ni}-\mathrm{Fe}$ batteries is cost-intensive and to a certain extent toxic (Berrow and Webber 1972; Beckett and Davis 1978; Tenório and Espinosa 2002). In this study therefore, as a proof-of-concept study, we have attempted to replace the nickel electrode with the carbonbased electrical-double-layer electrode to assemble an $\mathrm{Fe}-\mathrm{C}$ hybrid capacitor and have performance tested it. The Fe-C hybrid capacitor exhibits the stabilized capacitance of about $6 \mathrm{~F} \mathrm{~g}^{-1}$ over 100 cycles.

\footnotetext{
*Author for correspondence (akshukla2006@gmail.com)
}

\section{Experimental}

All the chemicals used in the synthesis were analytical grade and used without any further purification. The method by which the Fe active material was synthesized is reported elsewhere (Aravamuthan et al 2013). In brief, a mixture of $90 \mathrm{wt} \%$ of ferrous oxalate dihydrate and $10 \mathrm{wt} \%$ of polyvinyl alcohol was thermally decomposed in vacuum at $600^{\circ} \mathrm{C}$. In this study, all the electrodes used were fabricated using $0.5 \mathrm{~g}$ of $\mathrm{Fe}$ active material. The electrodes were prepared by mixing $83 \mathrm{wt} \%$ of Fe active material, $10 \mathrm{wt} \%$ of conducting graphite, $1 \mathrm{wt} \%$ of $\mathrm{Bi}_{2} \mathrm{~S}_{3}$ and $6 \mathrm{wt} \%$ polytetrafluoroethylene (PTFE $60 \mathrm{wt} \%$ dispersion in $\mathrm{H}_{2} \mathrm{O}$ ). The dough thus formed was spread and compacted at a compression of $67.5 \mathrm{kN}$ for 5 min onto a degreased $\mathrm{Ni}$ mesh of dimension $3.1 \times 3.3 \mathrm{~cm}^{2}$; the electrode thus obtained was sintered in $\mathrm{N}_{2}$ atmosphere at $350{ }^{\circ} \mathrm{C}$ for $45 \mathrm{~min}$. For formation of Fe electrodes, electrodes were assembled in a container with $6 \mathrm{M}$ aqueous $\mathrm{KOH}$ solution having $1 \mathrm{w} / \mathrm{v} \% \mathrm{LiOH}$ with nickel oxyhydroxide counter electrodes on either side of the iron electrode using mercury/mercuric oxide (MMO) as the reference electrode ( $E^{0}=0.098 \mathrm{~V}$ vs SHE) and cycled till constant discharge-capacity was established.

Thick ink made of AC (MeadWestvaco, USA) having a specific surface area of $1525 \mathrm{~m}^{2} \mathrm{~g}^{-1}$ was used as cathode in the hybrid capacitor assembly. The ink of AC was prepared using poly(vinylidenefluoride) (PVDF) as a binder in required amount of dimethylformamide (DMF) and $0.25 \mathrm{~g}$ of this ink was applied on either side of the graphite sheets of dimension $3.1 \times 3.3 \mathrm{~cm}^{2}$ that act as current collector. The electrodes were subsequently dried at $80^{\circ} \mathrm{C}$.

Cyclic voltammetry (CV) was performed using an Autolab Potentiostat/Galvanostat 302N instrument. The CV for Fe electrode in the $\mathrm{Fe}-\mathrm{C}$ hybrid capacitor 
assembly was carried out in a 3-electrode cell with $\mathrm{Fe}$ electrode as working electrode, AC electrode as auxiliary electrode and MMO as reference electrode. The measurements were carried out at the scan rate of $1 \mathrm{mV} \mathrm{s}^{-1}$ between a potential window of -1.2 and $-0.8 \mathrm{~V}$ vs MMO. During the CV studies, changes in the cell potential were measured. Based on the $\mathrm{CV}$ data for Fe electrode in the Fe-C hybrid capacitor assembly carried out in a 3-electrode cell, a potential window of 0.7 and $1.2 \mathrm{~V}$ is found to be safe for working with Fe electrode. The CV for AC-AC symmetric supercapacitor assembly was carried out in a 2-electrode cell at the scan rate of $10 \mathrm{mV} \mathrm{s}^{-1}$ between a potential window of 0 and $1 \cdot 2 \mathrm{~V}$.

Solartron analytical cell test system (Model 1470E, AMETEK, UK) was used to perform galvanostatic chargedischarge to check the effect of cycling on the capacitance of Fe-C hybrid capacitor. Galvanostatic charge-discharge studies were carried out at 15 and $20 \mathrm{~mA}$ for 100 cycles.

The electrodes used in this study were aged for about $24 \mathrm{~h}$ in the electrolyte before conducting any electrochemical tests on them.

\section{Results and discussion}

Thermal decomposition of the mixture of ferrous oxalate dihydrate and PVA yields a mixture of $\alpha$-Fe and $\mathrm{Fe}_{3} \mathrm{O}_{4}$ (magnetite) (Aravamuthan et al 2013). The Fe-C hybrid capacitor is constructed by placing carbon electrodes on either side of the iron electrode and immersing in $6 \mathrm{M}$ $\mathrm{KOH}$ aqueous solution having $1 \mathrm{w} / \mathrm{v} \% \mathrm{LiOH}$ as electrolyte. The anode (-ve plate) employs a formed Fe electrode exhibiting a specific discharge capacity of about $350 \mathrm{mAh} \mathrm{g}^{-1}$ at $100 \mathrm{~mA} \mathrm{~g}^{-1}$ with about $70 \%$ faradaic efficiency. During the charge and discharge of the capacitor the electrochemical reaction taking place at the iron electrode is

$$
\mathrm{Fe}+2 \mathrm{OH}^{-} \rightleftharpoons \mathrm{Fe}(\mathrm{OH})_{2}+2 \mathrm{e}^{-} .
$$

Reaction (1) shows a standard electrode potential of $-0.88 \mathrm{~V}$ vs SHE (Shukla et al 1994; Ravikumar et al 1996). AC cathode (+ve plate) is believed to exhibit electrical double layer capacitor (EDLC) behaviour by storing charge in virtue of double layer formed between the interface of micro-pores at the high surface area carbon electrode and the electrolyte. Though the exact processes taking place at the cathode are unknown, the possible reactions occurring at the interface in alkaline medium during charge-discharge is represented below

$$
2\left[\mathrm{C}^{+}-\mathrm{OH}^{-}\right]+2 \mathrm{e}^{-} \rightleftharpoons 2 \mathrm{C}+2 \mathrm{OH}^{-} \text {. }
$$

Since the faradaic reactions are not taking place at the interface, standard electrode potential for the cathode could not be measured. Based on the amount of charge stored $(Q)$ and capacitance $(C)$ exhibited by the EDLC, the potential $(V)$ at the interface can be deduced (Pell and Conway 2004; Chen 2013) from the relation

$$
V=\frac{Q}{C}
$$

The net reaction occurring during the operation of the hybrid capacitor can be given as

$$
\mathrm{Fe}+2\left[\mathrm{C}^{+}-\mathrm{OH}^{-}\right] \rightleftharpoons \mathrm{Fe}(\mathrm{OH})_{2}+2 \mathrm{C} .
$$

The cell potential for this hybrid capacitor is found to be dependent on the amount of charge stored at the interface of cathode and the efficiency of the faradaic reaction taking place at the anode.

A typical EDLC shows a rectangular profile for CV which is characteristic of the relation of current $I$ while passing through a capacitor with capacitance $C$ (Pell and Conway 2004; Chen 2013) given by

$$
I=C \frac{\mathrm{d} V}{\mathrm{~d} t} .
$$

In (5), $d V / d t$ is the scan rate. Normally, when a steady scan rate is maintained, a constant current passes through the system which switches instantaneously from positive to negative values as potential is changed forming a rectangular profile.

Figure 1 shows the $\mathrm{CV}$ for AC-AC symmetric supercapacitor assembly. The profile is leaf shaped indicating gradual charge-discharge behaviour due to the additional resistive components that could be attributed to the double layer formed at the electrode-electrolyte interface. During this study, $23.5 \mathrm{~F} \mathrm{~g}^{-1}$ of specific capacitance is observed.

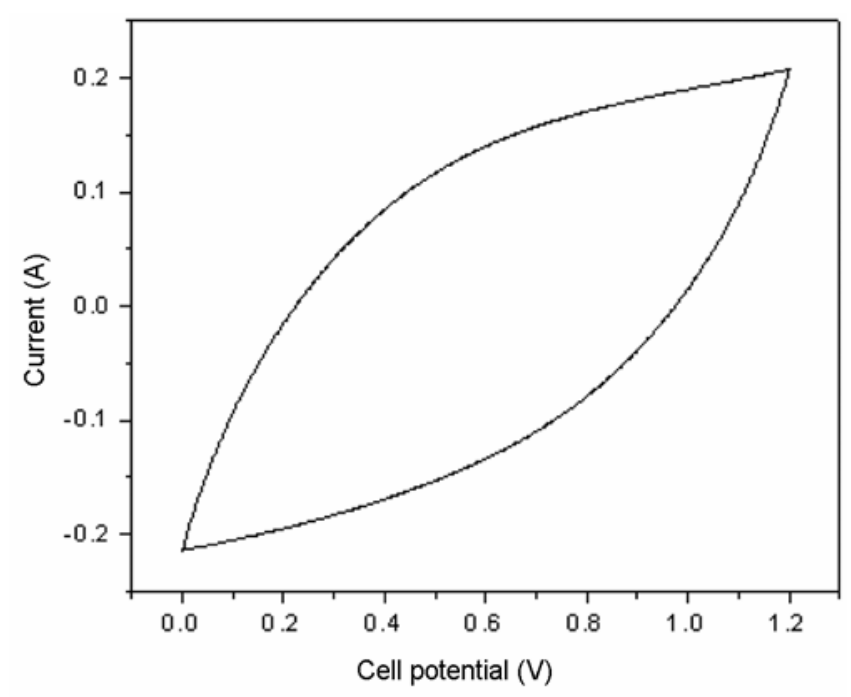

Figure 1. CV data obtained with a 2-electrode cell for AC-AC symmetric supercapacitor assembly at the scan rate of $10 \mathrm{mV} \mathrm{s}^{-1}$. 
The CV profile for Fe electrode is shown in figure 2. From the data, it is seen that the anodic sweep exhibits a peak between -0.9 and $-0.87 \mathrm{~V}$, while a peak is observed during cathodic sweep between -1.05 and $-1 \cdot 13 \mathrm{~V}$. These peaks can be attributed to the reversible dissolutionprecipitation of Fe active material (Geana et al 1974; Guzman et al 1979; Shukla et al 2001).

The capacitance exhibited by the hybrid capacitor is calculated using galvanostatic discharge data. It is observed that the capacitance exhibited by the hybrid capacitor shows an initial value of about $24 \mathrm{~F} \mathrm{~g}^{-1}$ at $15 \mathrm{~mA}$ discharge and about $17 \mathrm{~F} \mathrm{~g}^{-1}$ at $20 \mathrm{~mA}$ discharge which gradually reduces and stabilizes at about $6 \mathrm{~F} \mathrm{~g}^{-1}$. The variation in capacitance with cycling at 20 and $15 \mathrm{~mA}$ is shown in figure 3(a) and (b), respectively. It appears that during galvanostatic charge-discharge in $\mathrm{KOH}$ medium an insulating layer forms on the surface of the Fe electrode thereby limiting the electron-transfer reaction (Wang et al 2006). This could be attributed to the decrease in the capacitance shown by the capacitor with cycling.

The effect of cycling on the discharge profile for the cell, cathode and anode are shown in figure 4(a)-(c), respectively. From figure 4(a), it can be surmised that, with cycling, the time required for discharge decreases and, from cycle 40 onward, the change in the discharge profile indicates that the deep discharge of the Fe electrode sets in. Figure 4(b) and (c) shows the discharge profile for cathode and anode carried out at $15 \mathrm{~mA}$ for the $\mathrm{Fe}-\mathrm{C}$ hybrid capacitor. The single electrode potential of Fe electrode potential of $\mathrm{Fe}$ anode is monitored with respect to MMO during charge/discharge cycles. For convenience, to relate the cell potential and single electrode potential, the single electrode potential values are converted with respect to SHE. Fe is known to undergo two-step redox

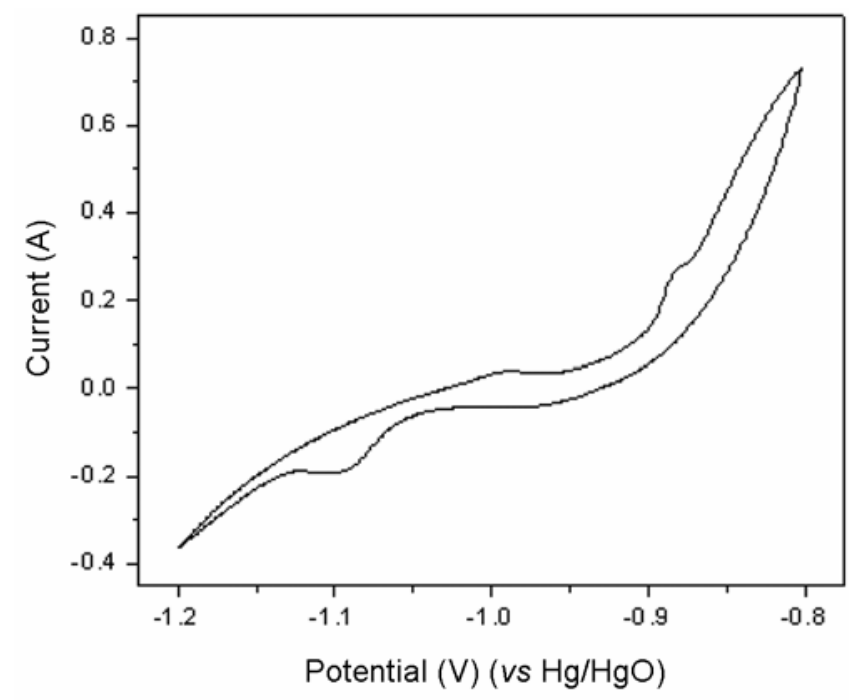

Figure 2. CV data obtained with a 3-electrode cell where Fe is working electrode, AC electrode an auxiliary electrode and $\mathrm{Hg} / \mathrm{HgO}$ as a reference electrode (scan rate $1 \mathrm{~m} \mathrm{~V} \mathrm{~s}^{-1}$ ). reactions during charge-discharge processes in alkaline medium as represented below.

$$
\begin{aligned}
& \mathrm{Fe}+2 \mathrm{OH}^{-} \rightleftharpoons \mathrm{Fe}(\mathrm{OH})_{2}+2 \mathrm{e}^{-}, \\
& \mathrm{Fe}(\mathrm{OH})_{2}+\mathrm{OH}^{-} \rightleftharpoons \mathrm{FeOOH}+\mathrm{H}_{2} \mathrm{O}+\mathrm{e}^{-} .
\end{aligned}
$$

The standard potentials for reactions (6) and (7) being -0.88 and $-0.56 \mathrm{~V}$ vs SHE, respectively (Shukla et al 1994; Ravikumar et al 1996).

It is also known that Fe electrodes have a tendency to charge slowly (Shukla et al 1994; Hariprakash et al 2005; Aravamuthan et al 2013). During this slow charging most of the $\mathrm{Fe}(\mathrm{OH})_{2}$ is converted back to metallic Fe and this could be one of the reasons for long cycle-life exhibited by the $\mathrm{Ni} / \mathrm{Fe}$ battery. By contrast, in $\mathrm{Fe}-\mathrm{C}$ hybrid capacitor assembly, when Fe electrode is charged at fast rate, it is observed that during initial cycles, namely 1-25
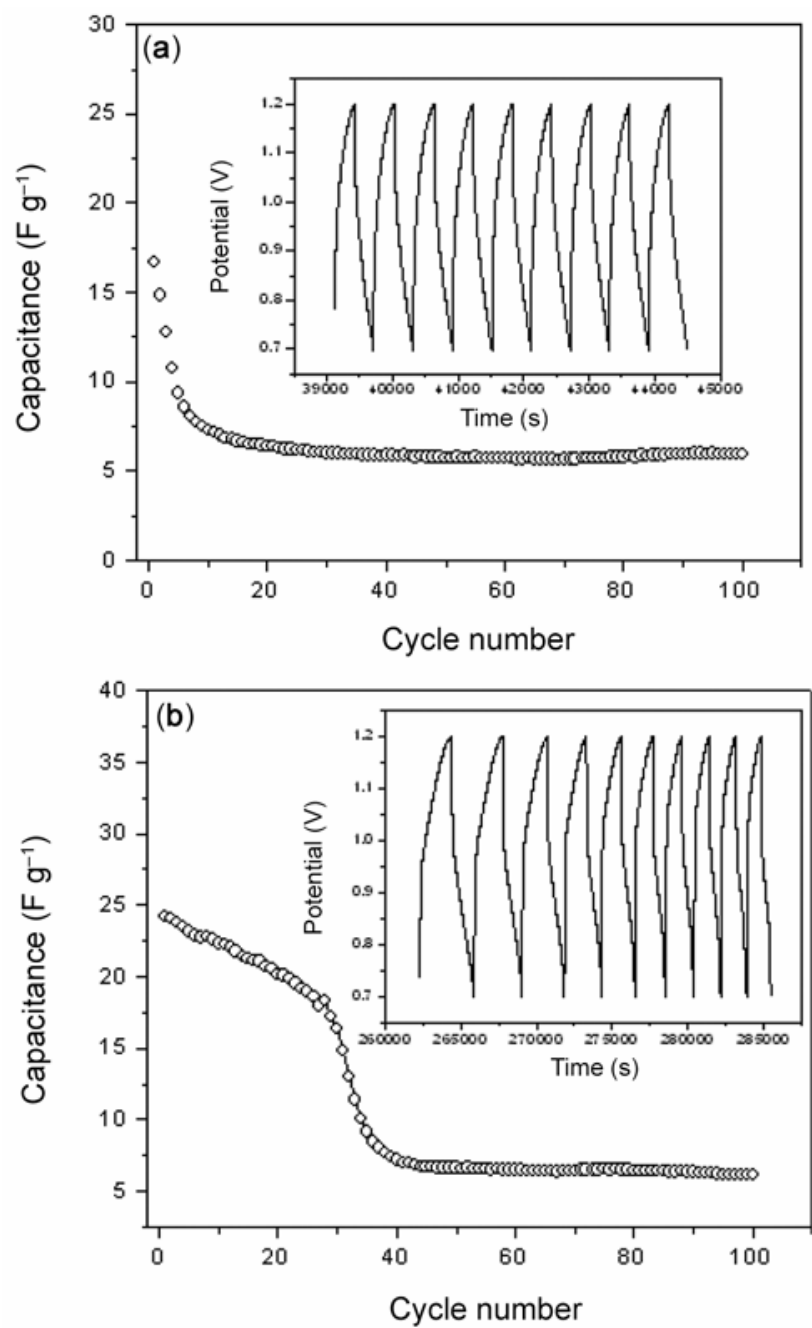

Figure 3. Variation of capacitance as a function of cycle number for $\mathrm{Fe}-\mathrm{C}$ hybrid capacitor. Inset shows the typical charge-discharge profiles for $\mathrm{Fe}-\mathrm{C}$ hybrid capacitor assembly: (a) at $20 \mathrm{~mA}$ and (b) at $15 \mathrm{~mA}$ discharge current. 

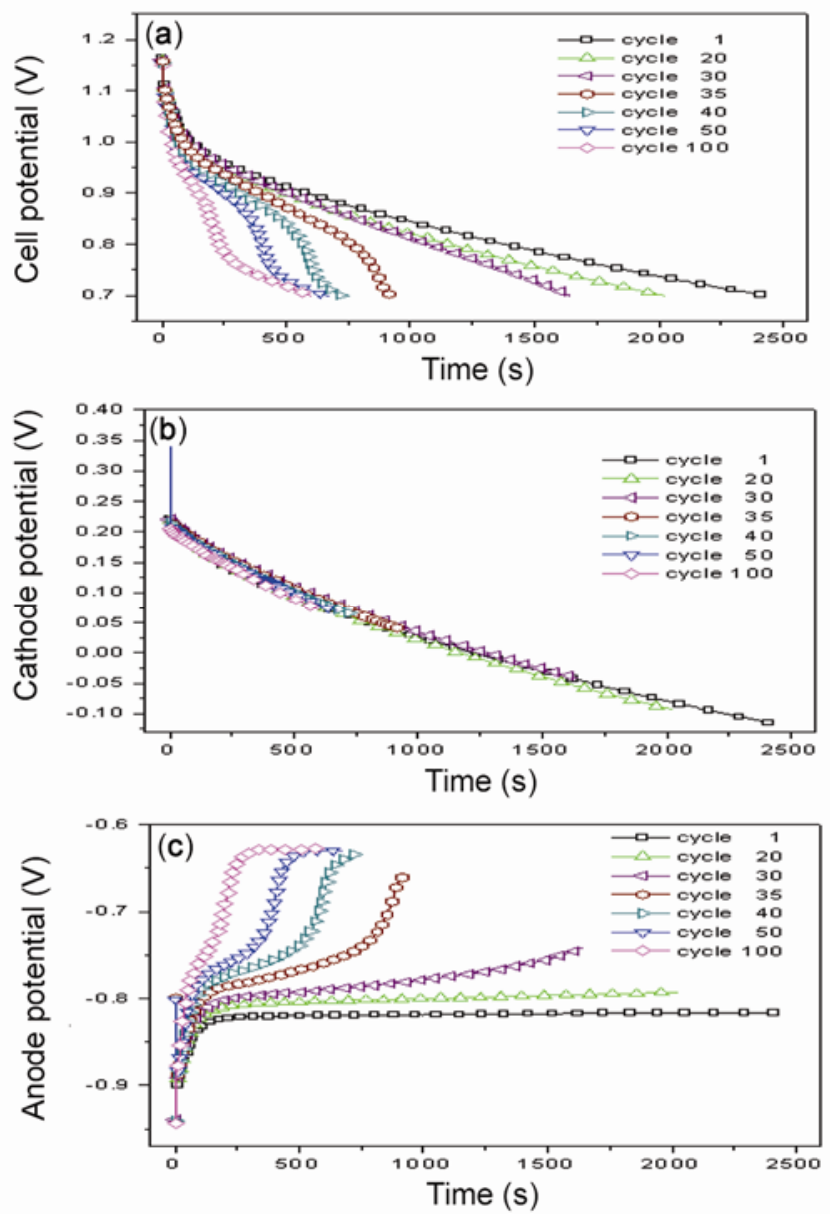

Figure 4. Effect of cycling on the discharge profile at $15 \mathrm{~mA}$ current: (a) in Fe-C hybrid capacitor cell assembly, (b) at cathode and (c) at anode.

cycles, there is a gradual decrease in the capacitance of the assembly followed by a steep decrease in capacitance during cycles 26-40 that finally culminates in stabilization of capacitance for remaining cycles as shown in figure 3(b). It can be derived from figure 4(c) that initially the discharge of the Fe electrode is limited in a potential regime where reaction (6) is dominating. With increasing cycles, insulating $\mathrm{Fe}(\mathrm{OH})_{2}$ layer builds up at the surface of the Fe electrode, due to consumption of $\mathrm{Fe}$ present at the surface. Besides, the insulating layer takes part in the redox reactions during charge-discharge cycles and forces the electrode to undergo reactions in potential region of reaction (7) causing deep discharge of Fe electrode. Based on the single electrode study carried out during discharge at $15 \mathrm{~mA}$ current, it may be surmised that the reduction in the initial capacitance with cycling could be attributed to insulating layer of $\mathrm{Fe}(\mathrm{OH})_{2}$ formed at the surface of the electrode. As seen from the data in figure 4(b), with cycling the discharge of AC is restrained which could be attributed to fast discharge of $\mathrm{Fe}$ electrode in an undesired potential regime.

\section{Conclusions}

The Fe-C hybrid capacitor of this study exhibits a stabilized capacitance of about $6 \mathrm{~F} \mathrm{~g}^{-1}$ over 100 galvanostatic charge-discharge cycles. The performance of the $\mathrm{Fe}-\mathrm{C}$ hybrid capacitor reported here is not fully optimized and further improvements are highly likely. The study provides a proof-of-concept for developing $\mathrm{Fe}-\mathrm{C}$ hybrid capacitors that may open newer applications.

\section{Acknowledgements}

The authors are grateful to the Department of Science and Technology (DST), Government of India and Indian Institute of Science, Bangalore, for financial support.

\section{References}

Aravamuthan S R, Srinivasan S and Shukla A K 2014 Energy Environ. Sci. 71110

Beckett P H T and Davis R D 1978 New Phytol. 8155

Berrow M L and Webber J 1972 J. Sci. Food Agric. 2393

Chen G Z 2013 Prog. Nat. Sci. 23245

Geana D, El Miligy A A and Lorenz W J 1974 J. Appl. Electrochem. 4337

Guzman R S, Viiche J R and Arvia A J 1979 Electrochim. Acta 24395

Hariprakash B, Martha S K, Hegde M S and Shukla A K 2005 J. Appl. Electrochem. 3527

Pell W G and Conway B E 2004 J. Power Sources 136334

Ravikumar M K, Balasubramanian T S and Shukla A K 1996 J. Appl. Electrochem. 261111

Shukla A K, Ravikumar M K and Balasubramanian T S 1994 J. Power Sources $\mathbf{5 1} 29$

Shukla A K, Venugopalan S and Hariprakash B 2001 J. Power Sources $\mathbf{1 0 0} 125$

Tenório J A S and Espinosa D C R 2002 J. Power Sources 10870

Wang H, Liang Y, Gong M, Li Y, Chang W, Mefford T, Zhou J, Wang J, Regier T, Wei F and Dai H 2012 Nat. Commun. 3917

Wang S, Ho K, Kuo S and Wu N 2006 J. Electrochem. Soc. 153 A75 